\title{
POLÍTICAS DE ESTÍMULO PARA A INOVAÇÃO EM PME PORTUGUESAS: CONTRIBUIÇÕES DA COTEC PORTUGAL
}

Josélia Elvira Teixeira ${ }^{1}$

Hélio Gomes De Carvalho

Walter Tadahiro Shima ${ }^{3}$

\footnotetext{
${ }^{1}$ Universidade Estadual do Centro-Oeste

${ }^{2}$ Universidade Tecnológica Federal do Paraná

${ }^{3}$ PROGRAMA DE PÓS-GRADUAÇÃO DE POLÍTICAS PÚBLICAS / SOCIAIS APLICADAS / Universidade Federal do Paraná
} 


\section{POLÍTICAS DE ESTÍMULO PARA A INOVAÇÃO EM PME PORTUGUESAS: CONTRIBUIÇÕES DA COTEC PORTUGAL}

Resumo: O regionalismo europeu desafia novas formas de governança multinível, que torna o processo de políticas para a inovação mais complexas. A criação da COTEC Portugal foi uma iniciativa da Presidência de Portugal e tornou-se a associação empresarial voltada para inovação mais importante no país. O objetivo deste trabalho foi analisar como os objetivos da COTEC Portugal se alinharam para contribuir com a inovação de pequenas e médias empresas. A pesquisa qualitativa deu-se por meio da pesquisa documental e por meio de entrevistas semiestruturadas na COTEC Portugal e representantes de nove empresas participantes da Rede PME Inovação. A COTEC congregou grandes empresas inovadoras. Para incentivar a participação das PME criou a Rede PME Inovação, consistindo na maior rede intersetorial voltada para inovação em Portugal. Integrar-se à COTEC tornou-se sinônimo no mercado de empresa inovadora, ampliação de networking e produzir uma autoavaliação dos seus processos de gestão de inovação.

Palavras-chave: Inovação. COTEC Portugal. PME. Políticas.

\section{Introdução}

$\mathrm{O}$ fenômeno da globalização econômica, financeira e produtiva intensificou-se nos anos 90, o que gerou expectativas positivas quanto ao crescimento e prosperidade mundial. Entretanto, o crescimento previsto foi frustrado no final da década, com o colapso da economia e no mercado de ações (STIGLITZ, 2003). Com o deslocamento dos recursos do âmbito produtivo real para o financeiro favoreceu o crescimento dos mercados de capitais. Isto se deu até mesmo em decorrência da dificuldade de crescimento do setor produtivo-real (GONÇALVES, 1999). O desafio para o setor produtivo de aumentar a competitividade e superar a crise fortalece o discurso de políticas que estimulem o aumento da produtividade e redução de custos e no bojo desta discussão entra a inovação como promotora de aumento de competitividade dos países e empresas.

O governo tem expandido suas funções desde Schumpeter e não é incomum que governos tenham financiado pesquisas universitárias, ou agências governamentais fazendo investimentos massivos nas áreas científicos e tecnológicos. Mas o que parece é ter crescido o interesse em articular políticas de ciência, tecnologia e inovação em parceria com a iniciativa privada (NELSON, 2006). A inovação não deve ser compreendida apenas como resultante da tecnologia, mas de forma mais abrangente, portanto, na forma como a inovação passa a ser compreendida é um tanto difusa, pois não é limitada a um departamento específico da empresa e deve ocorrer em diferentes níveis (KOTLER; DE BES, 2011).

Nesta perspectiva de estimular a parceria entre o governo e a iniciativa privada para inovar, a COTEC Portugal foi criada em 2003 pelo estímulo da Presidência de Portugal. A associação empresarial reuniu inicialmente as grandes empresas portuguesas altamente
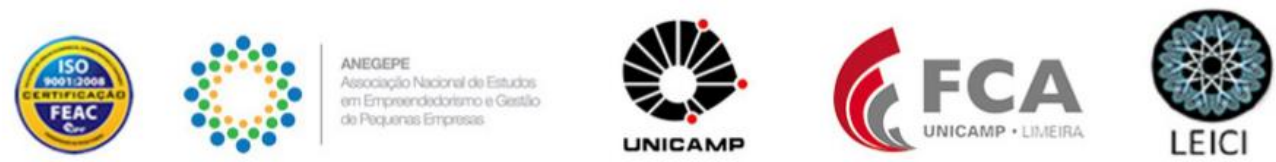
inovadoras. Entretanto, como a maioria dos países capitalistas, em Portugal a maioria das empresas é de porte pequeno e médio, desta forma sentiu-se a necessidade de elaborar uma ação específica que congregasse PME inovadoras à COTEC. Em 2005, surgia dentro da COTEC a Rede PME Inovação. Este artigo tem como objetivo analisar as contribuições da COTEC Portugal para a inovação destinada às PME, como forma interativa de políticas públicas e privadas. Para tanto, a metodologia utilizada foi a qualitativa, por meio de entrevistas semiestruturadas com os dirigentes da COTEC Portugal e de representantes de empresas associadas à Rede PME Inovação.

Este artigo está estruturado em seções, a introdução faz uma breve apresentação sobre o objetivo da pesquisa e problemas a serem discutidos neste artigo. O referencial teórico enfoca a concepção de inovação e como afeta as empresas pelo seu porte e estrutura de mercado, a terceira seção descreve brevemente os procedimentos da pesquisa e os resultados e discussão discorrem sobre as principais inciativas da COTEC Portugal e como seus projetos resultaram na formação da Rede PME inovação com o objetivo de agregar empreendimentos de pequeno e médio porte.

\section{Referencial Teórico}

\subsection{O reconhecimento da importância da inovação para a competitividade $e$ desenvolvimento}

Desde a década de 1980, numa economia pautada no conhecimento, se notam as rápidas mudanças de tecnologias e nos mercados. O empreendedorismo tornou-se um difusor do desenvolvimento e crescimento sustentável em uma economia pautada no conhecimento, sendo assim, motivo de discussão e inclusão na agenda política de vários países (DOHA; KIMB, 2014). Entretanto, somente o reconhecimento da importância da inovação e de seus benefícios não é suficiente, pois é necessário ter conhecimento sobre a melhor forma de aproveitar os ganhos e impactos da inovação em sua totalidade (FAGERBERG, MARTIN e ANDERSEN, 2013). Com efeito, a adoção de normas de classificação para inovação foi sintetizada no Manual de Oslo (OCDE-FINEP, 2004; OCDE; EUROSTAT- FINEP, 2005), que é um guia internacional de procedimentos para coligir e utilizar dados sobre inovação, especialmente, na indústria. O conceito de inovação desenvolvido por Schumpeter foi pedra angular no Manual de Oslo, sendo a inovação primordial para o desenvolvimento econômico. Portanto, a inovação não é apenas um conjunto de melhorias ou incremento de mudanças nas empresas. À medida que o conceito foi sendo refinado, ao longo do século XX aos dias atuais, nota-se a evolução da percepção do governo sobre a política de inovação. Colocava-se a ciência como motivadora do processo de inovação, e seria necessária uma política científica. No decorrer das últimas décadas, a perspectiva sistêmica veio substituir o modelo linear percepção simplificada de inovação.

Nelson e Winter apresentaram a busca de inovações como estratégia executada pelas empresas por meio de seleção dos seus resultados econômicos no mercado, que é o meio de seleção das inovações por excelência, e, em segundo plano, os institutos e as universidades. A concorrência neo-schumpeteriana se apresenta como um leque de oportunidades em si, as inovações são os elementos dinamizadores da economia e a estratégia consiste em criar diferenciação, o tempo todo. A generalização do conceito de inovação não se restringe ao

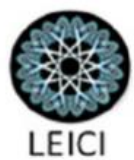


aperfeiçoamento tecnológico, mas se reflete na busca constante das empresas em obter vantagens competitivas frente aos concorrentes no mercado (POSSAS, 2002).

De acordo com Nelson (2006) o desempenho dos países em inovação frequentemente se mistura com o desempenho econômico e competitivo. Muitos estudos de países individuais têm buscado analisar o conjunto de políticas e programas governamentais de incentivo à inovação no setor produtivo. Segundo Dutz e Sharma (2012), a utilização de novas tecnologias aumenta de acordo com a capacidade de adaptabilidade aos contextos locais, o que torna o catching-up por meio das inovações cada vez mais perseguido por todos os países, pois é uma estratégia menos arriscada que a adoção de inovações de fronteira. Com isso, percebe-se redução de custos e incremento na competitividade, bem como, a inserção de novos produtos, processos, modelos de negócios e outros métodos e técnicas de marketing contribuem para criação de novos mercados e inserção naqueles já existentes.

Nesta perspectiva, a inovação se assenta no tripé: ciência, tecnologia e recursos humanos. A ciência permite a organização dos conhecimentos que, muitas vezes, resulta em uma nova tecnologia. A tecnologia pode ser considerada a condensação desses conhecimentos, formas, métodos, instrumentos e procedimentos, e que, por vezes, facilitam as escolhas das melhores e mais eficientes combinações dos inputs, sejam tangíveis ou intangíveis (DANTAS, 2001). Segundo Nelson (1993, p. 15, tradução nossa), "o avanço tecnológico ocorre por meio das interações de muitos atores". Essas interações envolvem vários componentes e o sistema de produtores, a montante e à jusante as firmas universidades e indústrias, agências governamentais, universidades e indústria. A evolução do conceito de inovação altera e combina modelos que traçam o processo de inovação. Diante dessas circunstâncias de evolução da concepção da inovação, as empresas alteraram suas estratégias segundo Rothwell (In: DODGSON; ROTHWELL, 1994). Chesbrough (2012) destaca a necessidade de criar e gerir a inovação em todos os portes de empresas e tipos de negócios. A empresa precisa inovar para garantir a sustentabilidade da empresa.

\subsection{Inovação e porte das empresas}

A literatura sobre a relação entre inovação com o porte das firmas foi vastamente explorada, no século XX. Schumpeter já havia apontado a discrepância do número de inovações de firmas grandes, conduzindo a discussão para as falhas de mercado e para a estrutura em que a firma está inserida. Entretanto, não é, necessariamente, uma condição sine qua non para que se mantenham o ritmo das invenções e inovações. Os estudos têm apresentado resultados controvertidos sobre a relação de tamanho da firma e inovações (NELSON, 2006). Isso decorre também pela diferença dos indicadores de medição. De acordo com Soete (1979 In: FREEMAN, 1990), os estudos realizados com o objetivo de determinar relação entre o tamanho das firmas e o aumento das atividades inovativas têm demonstrado resultados contrários à hipótese schumpeteriana.

As inovações podem ser criadas por indivíduos, pequenos grupos de empresas familiares ou grandes empresas, bem como centros de investigação públicos e privados ou universidades, organismos internacionais ou governos. Normalmente, as inovações estão associadas às grandes empresas, governos de países desenvolvidos e famosos centros de pesquisa, devido aos altos custos imputados às mesmas (BERUMEN, 2010). Vários estudos publicados desmistificam generalizações sobre o porte das empresas e capacidade inovadora,

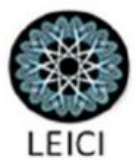


bem como, analisam a estrutura concorrencial em que a firma está inserida e o setor. Assim, também é possível ter um pouco mais de clareza sobre os fatores que aumentam a capacidade inovadora da firma ou os obstáculos que as mesmas precisam superar.

Kaplinsk (1983 In: FREEMAN, 1990) alertou para a existência de estudos amplamente estáticos, os quais observam apenas um determinado período e neles definem e projetam tendências e atribuem características. Na realidade, é mais complexo, pois não é possível designar se as grandes ou pequenas firmas são mais inovadoras, cabendo considerar um período e, adicionalmente, o ciclo de vida da indústria como uma medida. Neste mesmo prisma, Rothwell e Dodgson (1994) argumentaram que a relação de inovação com o porte de empresa, especificamente das PME, é fundamentalmente influenciada setorialmente. A capacidade inovadora de grandes e pequenas firmas varia relativamente com o ciclo de vida da indústria e, supostamente, com outros fatores adicionais como as mudanças tecnológicas das grandes e pequenas firmas. Antes disso, o estudo de Pavitt (1984 In: FREEMAN, 1990) sobre padrões setoriais da mudança técnica apresentava essa heterogeneidade de porte de empresas inovadoras por setores. Como exemplo citava-se o predomínio de empresas de grande porte na indústria eletrônica e química. Enquanto que, setores como o de mecânica e instrumentos de engenharia são compostos por pequenas empresas. Ainda, existem aqueles setores que combinam atividades entre grandes empresas e empresas pequenas.

As vantagens das grandes empresas, geralmente, estão associadas com seus recursos financeiros e tecnológicos. Apesar disso, as pequenas empresas apresentam vantagens ao que concerne o dinamismo empresarial, flexibilidade interna para mudanças circunstanciais que são vantagens comportamentais. As pequenas empresas destacam-se em áreas inovadoras como a aeroespacial, veículos motorizados, corantes, na construção de barcos e farmacêutica. Nestas áreas, inclusive ocorre, frequentemente, compartilhamento entre as pequenas empresas, devidos aos altos custos de P\&D (ROTHWELL; DODGSON, 1994).

Mowery e Rosenberg (2005) demonstraram que nos Estados Unidos, no pós-guerra, pequenas firmas foram importantes para o desenvolvimento e comercialização de novas tecnologias, como por exemplo, no ramo de computadores e de biotecnologia. Estes mesmos setores no Japão e na Europa Ocidental foram consolidados por grandes empresas. Estes mesmos autores citando Chandler (1990) e Pavitt (1990) que argumentaram sobre o predomínio das grandes empresas sobre novas tecnologias, nos Estados Unidos no pós-guerra, porém, necessita de mais atenção à trajetória dessas mudanças tecnológicas. Como exemplo, os avanços no campo dos semicondutores por grandes empresas, mas não se dá no momento da comercialização. Outra evidência é a contribuição das pequenas firmas tanto no desenvolvimento de novas tecnologias na área da biotecnologia como na comercialização de seus conteúdos.

A inovação tem se apresentado em vários portes de empresas. Os estudos abordados por Nelson (2006) observaram as trajetórias das empresas e das mudanças tecnológicas e a inovação pode ser mais evidente por porte de empresa de acordo com as características do setor e da estrutura concorrencial na qual a indústria se encontra. Nelson (2006) identificou nos estudos de diferentes países características peculiares no efetivo desempenho inovador. A primeira característica apontada foi que as empresas de um ramo são muito competitivas nos principais produtos que ofertam. Isto envolve desde a elaboração do projeto à produção, bem como a avaliação das necessidades dos consumidores e análise do mercado. Geralmente,

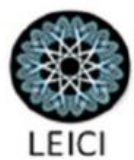


envolve alto volume de investimentos para dominar estas novas tecnologias e manter-se na liderança. Grande parte dos esforços em inovação é decorrente das próprias empresas.

Quanto à capacidade de inovação das empresas, Nelson (2006) afirma que a inovação não está necessariamente relacionada ao porte das empresas. Este autor salienta que há um consenso entre os economistas que em alguns ramos uma empresa precisa ser de porte grande para ter capacidade de inovar, em outros casos isso não acontece. Rothwell e Dodgson (1994) elencaram as principais vantagens e desvantagens das pequenas empresas em inovação. As empresas pequenas são menos burocráticas e têm maior agilidade na tomada de decisão e, assim, facilita uma resposta empreendedora. Há maior rapidez na comunicação interna e gera uma rede informal. Por outro lado, algumas vezes, falta maior formalização nas habilidades de gerenciamento do negócio, assim como, faltam tempo e dinheiro para estabelecer redes externas de ciência e tecnologia.

Rothwell e Dodgson (1994), em relação ao marketing da empresa, a vantagem se encontra nas respostas rápidas às mudanças exigidas pelo mercado e na possibilidade de dominar um nicho de mercado estreitoE considerando as finanças das PME a inovação pode ser menos custosa, podendo-se alocar o P\&D mais eficientemente. A organização das empresas é mais orgânica, simples e mais focada. Desta forma, a aprendizagem é mais rápida e incorpora-se mais facilmente nas rotinas e estratégias. $\mathrm{O}$ crescimento das pequenas firmas tem um potencial voltado para nichos estratégicos, onde as mesmas apresentam uma liderança técnica neste mercado, ou seja, capaz de oferecer outra diferenciação estratégica. Neste sentido, as PME tornam-se atraentes parceiros quando são líderes tecnológicos em algum ramo. Visando este potencial das PME, os governos vêm elaborando políticas públicas para subsidiá-las em projetos de inovação. A regulamentação, em alguns casos, é mais frouxa para as PME e, também, acaba sendo mais uma vantagem em ser pequena (ROTHWELL; DODGSON, 1994).

Por outro lado, as pequenas empresas têm recursos financeiros menores o que pode limitar o acesso de mercado start-up no exterior devido aos custos elevados. Outro aspecto é que, frequentemente, as PME não têm mão de obra com nível técnico alto e manter um departamento de P\&D também tem custos elevados. Assim, podem sofrer deseconomias de escopo em P\&D. Além disso, a inovação representa riscos financeiros elevados e acessar financiamento externo é problemático, à medida que o acesso é dificultado pelo alto custo do capital. Seus gestores são limitados em sua capacidade de gerir o que afeta a capacidade de crescimento das empresas. Outras desvantagens estão nas imposições intrínsecas às regulamentações vigentes, bem como a dificuldade de se lidar com o complexo sistema de patentes, que se tornam fortes barreiras à entrada. As políticas públicas e os esquemas estabelecidos nos departamentos governamentais podem, também, ser complicadores para a inovação em PME. As PME, ainda, apresentam dificuldades de estabelecer uma rede colaborativa com grandes firmas. Por fim, apresenta-se como desvantagem de ser pequena empresa para inovar, a menor capacidade de negociação com os fornecedores, pois têm menor poder de barganha (ROTHWELL; DODGSON, 1994).

\subsection{Inovações em PME em Portugal}
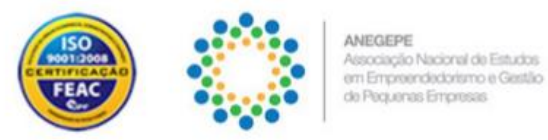

Realizadores:
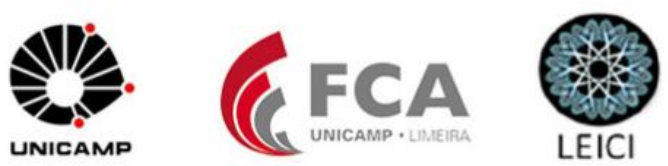
A designação de PME (Micro, Pequena e Média Empresa) em Portugal, está estipulada pelo Decreto Lei $n^{\circ} 372 / 2007$, de 06 de novembro de 2007. A literatura apresenta um amplo leque de autores abordando inovação em PME, ou seja, a abordagem dos estudos europeus utiliza-se dessa classificação. A Comissão Europeia utiliza-se dos mesmos parâmetros para definir as PME (IAPMEI, 2015). O Quadro 1 define o porte da firma, em Portugal, por números de colaboradores e volume de negócios:

QUADRO 1 - DEFINIÇÃO DE PME EM PORTUGAL

\begin{tabular}{|l|l|l|}
\hline Dimensão & $\mathbf{N}^{\mathbf{0}}$ Efetivos & $\begin{array}{l}\text { Volume de negócios ou Balanço } \\
\text { Total }\end{array}$ \\
\hline PME & $<250$ & $\begin{array}{l}\leq 50 \text { milhões de euros (VN) ou } \leq \\
43 \text { milhões de euros (BT) }\end{array}$ \\
\hline MICRO & $<10$ & $\leq 2$ milhões de euros \\
\hline PEQUENA & $<50$ & $\leq 10$ milhões de euros \\
\hline MÉDIA & $\begin{array}{l}\text { As PME que não são micro ou } \\
\text { pequenas empresas }\end{array}$ \\
\hline
\end{tabular}

Nota: Sendo que: valores finais de dimensão = Valores da empresa como autônoma + Valores do relacionamento relevante com outras empresas (quando existente).

FONTE: IAPMEI (2015).

De acordo com o Enterprise Europe Network (2015), a Comissão Europeia, por meio da recomendação 2003/361/CE, definiu microempresas, pequenas e médias empresas (PME) com o objetivo de promover o empreendedorismo, o investimento e o crescimento dessa dimensão de empresas. O acesso ao capital de risco é importante para o fortalecimento de PME, bem como, busca diminuir os encargos administrativos e promover a segurança jurídica. Essa nova definição comunitária de PME alterou a criada, em 1996, e entrou em vigor em janeiro de 2005, sendo recomendada pela Comissão Europeia aos Estados-Membros, especialmente, ao Banco Europeu de Investimento (BEI) e ao Fundo Europeu de Investimento (FEI) para que a utilizem. Vários mecanismos de apoio às PME europeias se alicerçam nesta definição de porte de empresa para conceder recursos. Entretanto, os Estados-Membros e as duas instituições financeiras supracitadas não são obrigadas a utilizar essa definição. Somente é obrigatória, em caso de solicitação das empresas de apoio estatal para gozar de benefício preferencial em relação às outras empresas, da mesma forma, quando se aplica fundos estruturais europeus e de programas comunitários. Segundo o IAPMEI (2015), no caso de comparações internacionais, pode-se tomar a base de dados do Eurostat, que classifica a dimensão das empresas de maneira simplificada, por meio do seu número de colaboradores.

A realidade de Portugal evidenciada pelo CIS de 2012 é que 54,5\% das empresas entrevistadas declararam-se ter desenvolvido alguma atividade de inovação. Embora o número de pequenas empresas e médias seja muito mais elevado, a prática da inovação é, consideravelmente, mais elevada nas grandes empresas com $84,6 \%$, enquanto $51 \%$ das pequenas empresas desenvolveram algum tipo de atividades de inovação e, respectivamente, $66,8 \%$ das médias. Quanto ao tipo de inovação que mais se destacou para as pequenas empresas foi a inovação de marketing, com 30,7\%, e para as grandes empresas foi a inovação de processo, com $68,8 \%$. Para as médias empresas a inovação de processo foi a mais elevada, com 46,5\% (TABELA 1).

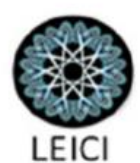


TABELA 1- ATIVIDADES DE INOVAÇÃO POR NÚMERO DE PESSOAS AO SERVIÇO EM PORTUGAL, 2010-2012 (\%) - INQUÉRITO COMUNITÁRIO CIS 2012

\begin{tabular}{lcccc}
\hline & $\begin{array}{c}\text { Pequena } \\
\mathbf{1 0 ~ a ~ 4 9}\end{array}$ & $\begin{array}{c}\text { Média } \\
\mathbf{5 0 ~ a ~ 2 5 0}\end{array}$ & $\begin{array}{c}\text { Grande } \\
\text { >= 250 }\end{array}$ & $\begin{array}{c}\text { Total } \\
\text { Nacional }\end{array}$ \\
\hline $\begin{array}{l}\text { Empresas com atividades de } \\
\text { inovação (1) }\end{array}$ & $51,00 \%$ & $66,80 \%$ & $84,60 \%$ & $54,50 \%$ \\
$\begin{array}{l}\text { Empresas com inovação de } \\
\text { produto e/ou processo (2) }\end{array}$ & $37,00 \%$ & $55,70 \%$ & $76,50 \%$ & $41,20 \%$ \\
$\begin{array}{l}\text { Empresas com inovação de } \\
\text { Produto }\end{array}$ & $22,40 \%$ & $37,30 \%$ & $62,20 \%$ & $25,90 \%$ \\
$\begin{array}{l}\text { Empresas com inovação de } \\
\text { Processo }\end{array}$ & $29,60 \%$ & $46,50 \%$ & $68,80 \%$ & $33,50 \%$ \\
$\begin{array}{l}\text { Empresas com inovação } \\
\text { Organizacional }\end{array}$ & $29,90 \%$ & $42,70 \%$ & $65,50 \%$ & $33,00 \%$ \\
$\begin{array}{l}\text { Empresas com inovação de } \\
\text { Marketing }\end{array}$ & $30,70 \%$ & $38,90 \%$ & $51,00 \%$ & $32,60 \%$ \\
\hline
\end{tabular}

Nota: Adaptado pela autora. 1) Inclui as seguintes atividades de inovação: produto; processo; atividades de inovação abandonadas ou incompletas; organizacional; e de marketing; 2) Inclui atividades de inovação abandonadas ou incompletas.

FONTE: DGEEC-MEC (2014a, p. 11).

Neste cenário de incertezas econômicas quanto à recuperação das economias, o empreendedorismo individual também se torna mais vulnerável às incertezas e riscos. Segundo o INE (2014), somente 23,2\% das empresas individuais conseguiram manter-se até o quarto ano de vida, enquanto que as sociedades aparecem com maior robustez para enfrentar os desafios do cenário econômico português. Foram 59,1\% dessas sociedades que sobreviveram até o quarto ano. Ou seja, mais de $30 \%$ no primeiro ano das empresas individuais (nos anos observados) não conseguem sobreviver. Percebe-se, também, que no ano de 2012 nasceram a menos 27,75\% empresas comparativamente com o ano de 2008 . Desse total de empresas, 1.126.344 eram PME. Ao categorizá-las por dimensão, 1.085.184 eram micro empresas, 35.529 eram pequenas empresas, 5.631 eram médias empresas e somente 973 eram classificadas como grandes empresas.

As causas da redução do número de empreendimentos, além da crise financeira de 2007-2008, estão associadas às dificuldades de recuperação dos indicadores macroeconômicos portugueses, além de imposições de austeridade fiscal ao governo português, o mercado interno pequeno (que também se estreitou com o cenário de crise) e à competitividade internacional (SIMÕES, ANDRADE e DUARTE In: ALEXANDRE et al. 2014). Esses fatores permitem aos leitores compreenderem melhor a posição competitiva de Portugal em relação à sua capacidade inovadora. De acordo com o INE (2016), em 2014 havia 1.127.317 empresas não financeiras localizadas em Portugal.

No caso de Portugal, quando se trata de políticas direcionadas à inovação é importante compreender também o contexto do regionalismo europeu. Atualmente, existem muitas 
políticas elaboradas para a Comunidade Europeia. Os países membros da Comunidade Europeia partilham de políticas que preveem o desenvolvimento em vários aspectos. $\mathrm{O}$ regionalismo também tornou-se um desafio por sua governança multinível, diversidade de atores e infraestruturas. O regionalismo estabelece valores, ideias e instituições para a comunidade convertendo o processo de implantação de políticas ainda mais complexo (COMISSÃO EUROPEIA, 2014). Na década de 90, Portugal passou por crescimento em diversos indicadores com os denominados programas estruturais. A combinação dos programas internos com os programas de financiamento público da comunidade europeia permeia a estratégia de desenvolvimento de Portugal desde 1989 (GAMA e FERNANDES, 2016). O Quadro de Referência Estratégico Nacional (QREN) constituiu o enquadramento para a viabilização da política comunitária de coesão econômica e social em Portugal, no período 2007-2013. Nesta perspectiva, busca-se elevar os níveis da eficiência e qualidade das instituições públicas (QREN, 2016). Gama e Fernandes (2016) apontam os três principais sistemas de incentivo que se concentram nos fatores de competitividade: Pesquisa e Desenvolvimento tecnológicos nas empresas, inovação e internacionalização das PME (SI Qualificação PME).

A Comissão Europeia - com representação em Portugal (COMISSÃO EUROPEIA PORTUGAL, 2015) anunciou, em 2014, um instrumento financeiro de garantia de empréstimo da União Europeia para as pequenas e médias empresas inovadoras. Este acordo denominado "InnovFin Garantia para as PME" foi assinado pelo Fundo Europeu de Investimento (FEI) e pelo banco português BPI. Este acordo está previsto pelo Horizonte 2020 (Programa-Quadro de Investigação e Inovação da UE) e prevê suporte de até 200 milhões de euros destinados às empresas inovadoras, nos dois anos subsequentes. Este mecanismo de financiamento oferece garantia e contrapartida para o financiamento da dívida de valores de 25 mil até 7,5 milhões de euros. O objetivo é facilitar o crédito para empresas inovadoras pequenas e médias (até 499 colaboradores). Nessa perspectiva de desenvolvimento socioeconômico e aumento da competitividade, várias instituições governamentais e não governamentais têm interagido para concretizar os objetivos programados e aumentar a competitividade da economia portuguesa e dos pequenos negócios. Destaca-se a presença da COTEC Portugal - Associação Empresarial para a Inovação que reúne empresas de todos os portes e de vários setores. Na próxima seção serão apresentados os objetivos dessa associação e como se articula para estimular a inovação em Portugal.

\section{Procedimentos metodológicos}

A pesquisa foi qualitativa e foram utilizados dados secundários por meio do Relatório Anual da COTEC. Além disso, entrevistas semiestruturadas com questões abertas que foram realizadas com os principais representantes da COTEC Portugal: Diretor Geral da COTEC Portugal Dr. Daniel Bessa; Diretora de Projetos e Coordenadora do Barômetro da Inovação

\footnotetext{
${ }^{1}$ InnovFin Garantia para as PME está previsto dentro do InnovFin - Financiamento da União Europeia para Inovadores, que é "a nova geração de instrumentos financeiros da UE e de serviços de aconselhamento desenvolvida no âmbito do Programa-Quadro Horizonte 2020 para facilitar o acesso ao financiamento por parte de empresas inovadoras" (COMISSÃO EUROPEIA -PORTUGAL, 2015).
}

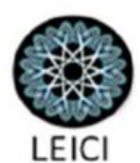


Dra. Isabel Caetano e o responsável pela Rede PME Inovação Eng. Carlos Cabeleira. Essas entrevistas foram realizadas por meio de telefone, webconferência via Skype e $e$-mail.

Para as empresas participantes da Rede PME Inovação foram utilizados questionários semiestruturados com questões abertas (com a expectativa de que o responsável falasse e desse o máximo de contribuições) e fechadas com o intuito de ter uma melhor percepção sobre a inovação na empresa. Os representantes das empresas aceitaram responder as questões pessoalmente ou por meio do e-mail. Todas estas empresas são consideradas pela COTEC Portugal inovadoras, pois passam por um processo de avaliação na candidatura à Rede. Algumas das questões fechadas para as empresas foram elaboradas a partir do questionário da Redesist, que é uma Rede de pesquisa em sistemas e arranjos produtivos e inovativos locais, da Universidade Federal do Rio de Janeiro (UFRJ), mas conta com a colaboração de outras instituições e seus pesquisadores (REDESIST, 2016). As empresas foram convidadas aleatoriamente, de acordo com a disponibilidade de e-mail das associadas à Rede PME Inovação no site da COTEC Portugal. Foram convidadas 35 empresas, entretanto, somente nove aceitaram participar respondendo as questões, no período de outubro de 2015 a janeiro de 2016. As empresas são empresas de regiões diferentes de Portugal, tais como: Coimbra, Lisboa, Braga, Madalena - Vila Nova de Gaia, Alcanede. A Figura 1 permite visualizar os procedimentos utilizados na pesquisa qualitativa:

\section{FIGURA 1 - PROCEDIMENTOS DE COLETA DE DADOS DA PESQUISA QUALITATIVA}

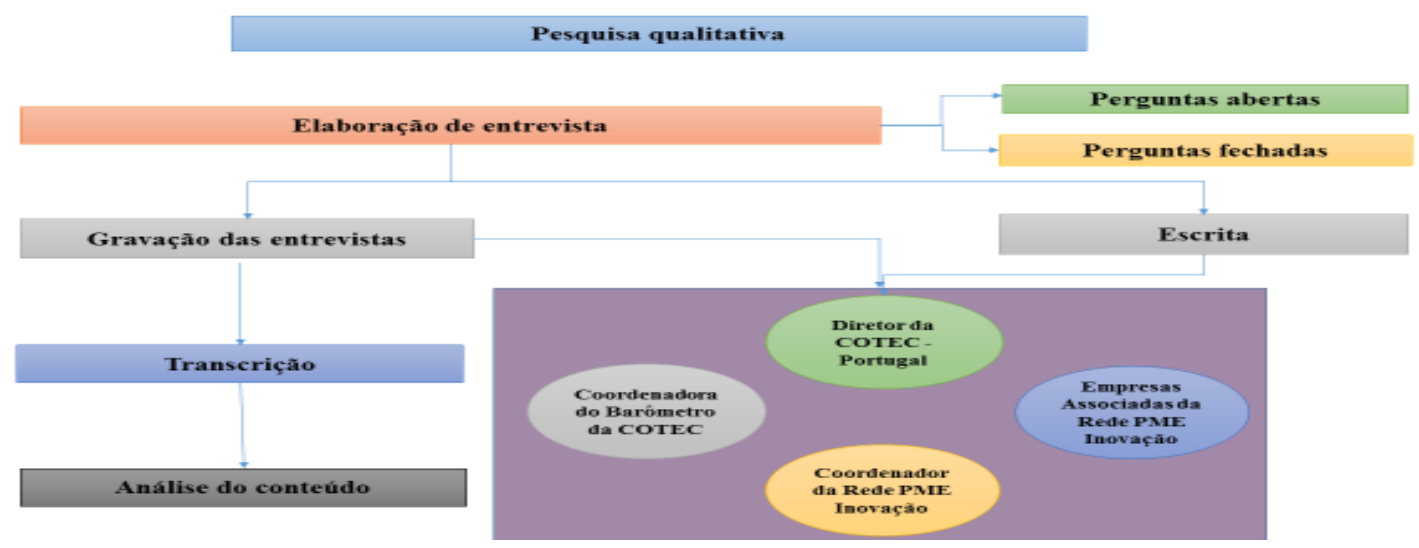

FONTE: Elaboração própria (2016).

As nove empresas associadas à Rede PME Inovação, que concederam entrevista, são de diversos setores, tais como: Metal-mecânico, Telecomunicações, Software, Iluminação, Tecnologia da informação e Gestão e consultoria.

\section{Resultados e discussões}

4.1 A COTEC - Associação Empresarial para a Inovação e seus objetivos de estímulo à inovação em Portugal

A COTEC Portugal- Associação Empresarial para a Inovação foi fundada, em 2003, e tem um caráter especial, por ser uma associação privada, derivada de uma iniciativa pública

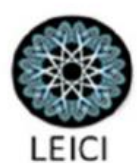


por meio de um decreto da Presidência da República, e assinado pelo presidente Jorge Sampaio. Tem sua sede em Porto e delegação em Lisboa. Sua missão é incentivar a competitividade das empresas portuguesas, por meio da difusão e práticas de ações inovadoras. A associação contava em 2015366 associados e não possui fins lucrativos. O ambiente em que o projeto da COTEC se insere envolve vários atores do SNI português o que torna mais complexo analisar os condicionantes que são imperiosos para a inovação, tais como: as empresas associadas da COTEC Portugal entre outras não associadas, estruturas associativas e instituições públicas (COTEC, 2015a).

No plano europeu, a COTEC Portugal mantém parcerias com suas análogas COTEC Espanha e Itália e desenvolveram projetos comuns para incentivar a inovação. No âmbito interno, tem um papel notadamente reconhecido no SNI português. As primeiras empresas que se associaram à COTEC, juntas correspondiam em termos de valor adicionado bruto a $18 \%$ do PIB de Portugal. Uma iniciativa pública com organização privada para promover, na prática, a cultura da inovação. Desde a sua fundação, a COTEC atraiu empresas de destaque econômico e inovadoras como associadas (COTEC, 2015a). A COTEC Portugal (2015a) estruturou, em 2003 e 2004, como objetivos estratégicos de seu plano de ação os seguintes eixos: a) incentivar a cultura da inovação empresarial; b) aumentar a implementação da inovação pelos diferentes atores do Sistema Nacional de Inovação (SNI); c) assistir as formulações estratégicas dentro do SNI e Europeu; e d) reduzir impedimentos para a inovação.

Neste sentido, para o cumprimento dos eixos estruturantes o artigo $4^{\circ}$ do Estatuto da COTEC define como atribuições da associação: a COTEC terá um papel ativo relativo à formulação de estratégias de investimento em inovação no país, bem como será uma entidade promotora de análise dos principais fatores dos processos de inovação no desenvolvimento socioeconômico. Entre essas atividades que serão capazes de conduzir as instituições públicas e privadas à reflexão sobre a inovação, cabe a COTEC desenvolver diagnósticos pertinentes sobre o ambiente macro e micro da inovação nacional. Outro aspecto fundamental é o de incentivar e sensibilizar as empresas para a alocação de recursos em pesquisa, desenvolvimento e inovação. A Associação procura incentivar as empresas nacionais a inovarem, entretanto, de forma mais sistemática, eficiente e eficaz. Nesta linha, a COTEC no âmbito do Desenvolvimento Sustentado da Inovação Empresarial (DSIE) elaborou quatro projetos (COTEC, 2007):

- Projeto 1: Identificação e difusão de modelos e mecanismos empresariais indutores do desenvolvimento sustentado;

- Projeto 2: Definição de uma metodologia de classificação das atividades de pesquisa, desenvolvimento e inovação;

- Projeto 3: Certificação da gestão da pesquisa, desenvolvimento e inovação;

- Projeto 4: Desenvolvimento de um sistema denominado Innovation Scoring.

Estabelecidos os projetos, a COTEC produziu resultados concretos com suas equipes de trabalho. Os projetos tiveram por base teórica o Modelo de Interações em Cadeia, de Caraça, Lundvall e Mendonça (2008). Portanto, a COTEC, nesse papel de articuladora de atores dentro do SNI português, tem o desafio de estimular os agentes a investir em inovação, como estratégia competitiva como resposta à crise. Bessa (2016) ressalta o papel que a COTEC assumiu no SNI português e dos projetos propostos para estimular as empresas

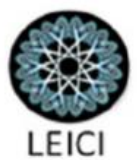


associadas e os outros atores envolvidos no processo de dinamização da inovação na economia portuguesa. A COTEC estruturou-se com a perspectiva de estimular a dinamização da inovação empresarial, e desta forma, contribuir para a aceleração do crescimento das PME e desenvolver projetos. Portanto, qualquer empresa que queira associar-se à COTEC, desde que resida em Portugal e não tenha nenhum impedimento, pode solicitar a sua adesão à Associação (COTEC, 2015). De acordo com Isabel Caetano, Diretora de projetos e coordenadora do Barômetro da Inovação, não existe um perfil característico das empresas associadas à COTEC, porém, as empresas da Rede PME Inovação são selecionadas de acordo com a pontuação no Innovation Scoring.

Isabel Caetano explica que estava coordenando uma área de trabalho dentro da COTEC denominada "Dinamização da inovação empresarial”. Esta linha de trabalho pretende reforçar as competências das empresas na gestão da inovação, respeitando o grau de maturidade de cada empresa, e a equipe da associação contribui com a identificação da trajetória que cada empresa se encontra. Para isso, está disponível gratuitamente o Innovation Scoring, o qual parametriza o diagnóstico da gestão da inovação de cada empresa. Entretanto, a COTEC não serve como um substituto de empresas de consultoria ou o papel das universidades ou institutos. Por meio do Innovation Scoring é possível que a empresa faça o diagnóstico de seus pontos fortes e/ou áreas de potencial melhoria (CAETANO, 2015, Informação verbal). Após a realização do diagnóstico, as empresas podem analisar quais são os principais determinantes internos de inovação. O próximo passo é a análise dos recursos disponíveis (financeiros, humanos, networking ou outros) que sejam fundamentais para a viabilização da inovação dentro da empresa, sob a perspectiva das dimensões de inovação estabelecidas no Innovation Scoring: Cultura, Liderança e Estratégia de Inovação. Após essa análise, a próxima etapa é a averiguação dos principais processos que podem sustentar a dinâmica da inovação. Por fim, a empresa avalia seus resultados, que consiste no objetivo da COTEC, ou seja, a COTEC está empenhada em contribuir com a geração de valor nas empresas. Portanto, a COTEC compreende a gestão da inovação como a transformação do conhecimento em valor econômico e social (CAETANO, 2015, Informação verbal).

A COTEC realiza surveys nas empresas associadas, que permitem avaliar o grau de maturidade das empresas associadas em matéria da gestão de inovação. Os resultados das ações da COTEC denotam que existe a necessidade de aplicação de métricas e formulação de indicadores de inovação empresarial que auxilie a própria COTEC nos comparativos. A presença da comunidade científica, especialmente no que tange aos estudos econométricos e de outra natureza, relacionados à realidade da inovação em Portugal, também se faz necessário. Entretanto, essa colaboração e envolvimento ainda não se consolidaram. O diminuto número de funcionários da COTEC também limita a concretização das ações que se estendem por todo o território nacional e do papel da mesma no SNI. A crise econômica também afetou o gasto das empresas com inovação, pois poucas têm um comportamento anticíclico (CAETANO, 2015, Informação verbal).

Sendo o mercado português pequeno, as empresas mais inovadoras têm o desafio constante de atingir uma perspectiva internacional. As empresas associadas à COTEC são bastante internacionalizadas. $\mathrm{E}$ as empresas que estão se associando estão com essa perspectiva de atingir novos mercados. É um processo contínuo que está em construção. No entanto, criar uma cultura que promova a inovação nas empresas se faz paulatinamente e é um

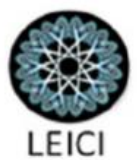


desafio. A COTEC tem esse objetivo de promover uma rede colaborativa entre as empresas, o que não existia antes em Portugal. Por meio da COTEC intermedia-se a partilha de gestão de ideias entre as empresas e isso permite queimar etapas e acelerar os processos dentro das organizações (CAETANO, 2015, Informação verbal). A COTEC considera as empresas como learning organizations, ou seja, empresas que estão dispostas a aprender com outras organizações que já passaram por um determinado processo ou estão passando por implementação de sistemas de gestão da inovação mais robustos e que possam ser compartilhadas as experiências. A Associação proporciona instrumentos de partilha de experiências tais como o Barômetro da Inovação e o Guia de Boas Práticas de Inovação. O caso da aplicação da metodologia "Comunidade de práticas da gestão da inovação", no qual se usou de sessões presenciais e on-line, por meio da web para reforçar o tema com o intuito de possibilitar as interações e construção de networking para as empresas (CAETANO, 2015, Informação verbal).

\subsection{A formação da Rede PME Inovação da COTEC Portugal}

Considerando o grande potencial inovador das PME e o grande número de empresas deste porte, em Portugal, além de possuírem um papel, indubitavelmente, importante na geração de renda e emprego na economia portuguesa, a COTEC criou, em 2005, a Rede PME Inovação. Iniciou a rede com 24 membros e até 2015 estava composta por 272 empresas. A Rede tem como objetivos evidenciar o grupo de PME por suas habilidades e competências em atividades inovadoras, concretizar a formação da Rede para possibilitar a cooperação entre as empresas que são associadas da COTEC Portugal e as PME da Rede e finalmente, dar suporte específico nas etapas de crescimento das empresas, atraindo investimentos e também apoiando a internacionalização dessas empresas, devido ao mercado consumidor pequeno, de Portugal (COTEC, 2016).

Para integrar-se à Rede PME Inovação é necessário que a PME tenha faturamento superior a 200 mil euros para candidatar-se. Na candidatura precisam passar pelo processo de avaliação que é a ferramenta denominada Innovation Scoring. Além disso, para a sua permanência também se exige participar nos custos da Rede PME Inovação, determinados pela direção da COTEC Portugal. A composição da Rede PME Inovação está apresentada no Relatório de Contas de 2014 e de 2015. Nota-se, em 2014, que nove empresas foram desligadas, mas 35 novos membros foram selecionados para compor a rede. Além disso, uma empresa da Ilha da Madeira foi integrada à Rede, passando a abranger mais uma região geográfica de Portugal. Novos integrantes compondo a Rede demonstra que as empresas seguem com interesse na associação intersetorial. Em 2014 eram 252 associados e passaram para 272 empresas integrantes em 2015 (COTEC PORTUGAL, 2016).

De acordo com esse mesmo Relatório de Contas de 2015 (COTEC Portugal, 2016), a maior concentração de empresas na Rede é na área de Tecnologias da Informação e Comunicação (TIC), que corresponde a 32\% da totalidade das empresas. Em segundo lugar empresas de equipamento industrial com $10 \%$ e, respectivamente, com igualmente $8 \%$ cada, os segmento de empresas de agricultura e alimentos, empresas de plásticos e moldes correspondem a 7\%. As demais empresas são dos seguintes setores: Eletrônica, Consultoria, Biotecnologia, Farmacêutica, Medicina, Calçado, Construção Civil, Têxteis e Vestuário, Metal-mecânico, Mobiliário, Produção de Energia, Ambiente, Engenharia de Materiais,

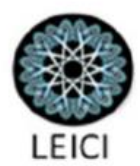


Química e Tintas, Cortiça, Climatização, Design, Eletrodomésticos, Engenharia Aeroespacial, Processamento de Madeira, Produtos de limpeza, Publicidade e Marketing, Serviços Florestais, Arquitetura, Borracha, Cerâmica, Construção de Elevadores, Construção de embarcações, Engenharia de Processos, Higiene e Cosmética, Iluminação, Produção de Capacetes, Produção de Lápis, Produção de Lentes, Serviços Financeiros e Telecomunicações. Devido ao reduzido mercado português, nota-se que essas empresas têm se esforçado para atingir o mercado internacional. Essas empresas exportam para o mercado europeu e extracomunitário. Ressalta-se que, em média, essas empresas exportaram $42 \%$ do total do volume de negócios. Estas empresas integrantes da Rede compõem o número reduzido da média de PME portuguesas que são exportadoras. Um dos objetivos da rede é também contribuir para as PME crescerem e também estimular essas empresas a entrar no mercado internacional.

A Rede PME Inovação tem por objetivo criar um ambiente favorável para o estabelecimento de networking, não somente com as outras PME, mas com as grandes empresas associadas. Além de propor o compartilhamento de expertise, abrir canais de distribuição e possibilidades de interação em projetos colaborativos, também dá visibilidade às empresas participantes da mesma. Estas questões foram abordadas nas entrevistas com nove empresas associadas da Rede PME Inovação, as quais se localizam em diferentes cidades de Portugal. Essa ideia de rede é valorizada por Julien (2013) ao afirmar que, por meio de vários estudos, está consolidada a ideia de que os empresários e as empresas não estão ilhados, e que o seu desenvolvimento é também função de outras empresas que fazem negócios. $\mathrm{O}$ aumento do número de empresas é decorrente de uma atmosfera propícia, e isso necessita que os principais atores acreditem na importância das pequenas empresas locais. A empresa nasce das ideias dos empresários, mas as redes que essas empresas estão inseridas contribuem para esse ambiente propício.

A COTEC criou a Rede PME Inovação para alcançar, de forma mais efetiva, este porte de empresas, que correspondem a 99\% das empresas em Portugal, mas efetivamente as ações no desenho dos projetos elaborados pela COTEC são mais de aproximação das grandes empresas das PME do que projetos dotados de singularidades específicas com um direcionamento por porte de empresas. Carlos Cabeleira (2015, informação verbal), engenheiro e responsável pela coordenação da Rede PME Inovação, quando indagado sobre se a COTEC compreende que existe a necessidade de diferenciar ações para incentivar a inovação por porte de empresas.

Um dos objetivos ressaltados nas entrevistas junto às empresas foi a criação de networking e o próprio aprendizado. A Rede PME Inovação oferece como atividade o "Dia do Associado", em que as grandes empresas abrem as portas paras as PME. Embora, sendo uma rede intersetorial, a oportunidade de aprendizagem, e de principalmente saltar etapas, para agilizar o processo de aprendizado e inovação, com empresas que geralmente não concederiam esse intercâmbio com outras, torna a rede uma via concreta entre as trocas de aprendizagem. As empresas apresentam uma grande capacidade inovativa e de interação colaborativa com outros atores como empresas, institutos de pesquisa e universidades, mas não usam a Rede PME Inovação nem a COTEC como instituição promotora de seu networking, embora seja um dos motivos que as levou a participar da Rede. Das nove empresas entrevistadas apenas duas empresas relatam que estabeleceram parcerias com outras

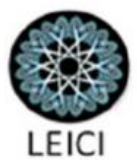


empresas da própria rede, o que torna uma incongruência com o próprio objetivo de aumentar sua networking. Denota-se que estas empresas são bem articuladas e possuem relação de parceria com outros atores do SNI português, inclusive, algumas dessas empresas descreveram parcerias para desenvolvimento de produtos e processos inovadores com empresas, universidades e institutos internacionais.

\section{Considerações finais}

A iniciativa da Presidência de Portugal em incentivar a criação da COTEC Portugal Associação Empresarial para a inovação é um exemplo de interação de políticas públicas e iniciativa privada e decorre da necessidade de coordenar os diferentes atores dentro do SNI e estimular a inovação frente aos desafios de superar as crises e aumentar a competitividade, até mesmo respondendo à coordenação de políticas de promoção de competitividade e desenvolvimento no âmbito do regionalismo europeu.

A COTEC Portugal reuniu as grandes empresas inovadoras e tornou-se uma referência no país e internacionalmente. As empresas associadas passam por uma candidatura em que precisam avaliar suas competências e habilidades inovadoras. Entretanto, face ao cenário em que prevalecem PME, criou-se a Rede PME Inovação, para atender mais especificamente as peculiaridades dos pequenos e médios empreendimentos. A iniciativa tornou-se exitosa, pois reuniu a maior rede de empresas inovadoras intersetorial do país. A associação criou instrumentos de partilha de práticas e experiências, na expectativa de galgar saltos e acelerar o processo de aprendizagem das organizações. O desafio consiste em atender o território nacional com os poucos funcionários e estar ampliando o leque de opções para expandir a interação da rede. Além disso, a COTEC auxilia na orientação e formulação de políticas para a inovação e na coordenação e interação de diferentes atores no SNI português.

\section{Referências}

BERUMEN, Sergio A.. Economía de la empresa innovadora. Lima: Universidad Esan, 2010.

BESSA, Daniel. COTEC Portugal. Entrevista por e-mail. Entrevistador: Josélia E. Teixeira. Coimbra, 2016. Informação verbal.

CABELEIRA, Carlos. COTEC Portugal. Entrevista por skype. Gravação em MP3. Entrevistadora: Josélia E. Teixeira. Coimbra, 2015. Informação verbal.

CAETANO, Isabel. COTEC Portugal. Entrevista por skype. Gravação em MP3. Entrevistadora: Josélia E. Teixeira. Coimbra, 2015. Informação verbal.

CARAÇA, João; LUNDVALL, Bengt- Åke; MENDONÇA, Sandro. The changing role of science in the innovation process: From Queen to Cinderella. Technological Forecasting \& Social Change. Elsevier, Ago. 2008.

CHESBROUGH, Henry William. Inovação aberta: como criar e lucrar com a tecnologia. Porto Alegre: Bookman, 2012.

COMISSÃ̃ EUROPEIA. Compreender as políticas da União Europeia: como funciona a União Europeia - guia das instituições da União Europeia. Luxemburgo: União Europeia, 2014. 
COMISSÃO EUROPEIA - PORTUGAL. InnovFin Garantia para as PME. 22 dez. 2014. Disponível em:

http://ec.europa.eu/portugal/comissao/destaques/20141222_innovfin_garantia_pme_pt.htm>

Acesso em: 24 nov. 2015.

COTEC PORTUGAL. Innovation Scoring: Manual de apoio ao preencimento. Portugal: COTEC Portugal, 2007.

COTEC PORTUGAL. COTEC PORTUGAL Associação Empresarial para a inovação. Disponível:

$<$ http://www.cotecportugal.pt/index.php?option=com_content\&task=blogcategory\&id=69\&It emid=109>. Acesso em: 03 jun. 2015a.

$\begin{array}{lllll}\text { COTEC PORTUGAL. } & \text { Relatório } & \text { e } & \text { Contas }\end{array}$

Disponível:<http://www.cotecportugal.pt/pt/quem-somos/relatorio-e-contas/relatorio-de-

contas-de-2015> Acesso: 01 nov. 2016a.

DANTAS, José. Gestão da inovação. Porto: Vida Econômica, 2001.

DIREÇÃO GERAL DE ESTATÍSTICAS DA EDUCAÇÃO; CIÊNCIA DIREÇÃO DE SERVIÇOS DE ESTATÍSTICA DA CIÊNCIA E TECNOLOGIA E DA SOCIEDADE DE INFORMAÇÃO - DGEEC/MEC. Sumários Estatísticos: CIS 2012 - Inquérito Comunitário à Inovação. Lisboa: Direção Geral de Estatísticas da Educação, 2014a.

DOHA, Soogwan; KIMB, Byungkyu. Government support for SME innovations in the regional industries:The case of government financial support program in South Korea. Research Policy. Jun. 2014.

DUTZ, Mark A.; SHARMA, Siddharth. Green Growth, Technology and Innovation. World Bank Policy Research Working Paper. No 5932. January - 1, 2012. Disponível em: < http://papers.ssrn.com/sol3/papers.cfm?abstract_id=1980586> Acesso: 28 ago. 2015.

ENTERPRISE EUROPE NETWORK. Definição europeia de PME. Disponível:< http://www.enterpriseeuropenetwork.pt/info/polserv/pol\%C3\%ADticas/Paginas/p1.aspx>

Acesso em: 16 dez. 2015.

FAGERBERG, Jan; MARTIN, Bem R.; ANDERSEN, Esben S.. Innovation Studies: towards a New Agenda. Oxford: Oxford University Press, 2013.

GAMA, Rui; FERNANDES, Ricardo. Políticas públicas de inovação em Portugal - uma análise do QREN. Universidade de Coimbra. Disponível: $<$ https://estudogeral.sib.uc.pt/bitstream/10316/23262/1/8CGP_Gama_Fernandes_V_final.pdf $>$ Acesso em: 10 fev. 2016.

GONÇALVES, Reinaldo. Globalização e desnacionalização. São Paulo: Paz e Terra, 1999.

NELSON, Richard. National Innovation Systems: a comparative analysis. New York: Oxford University Press, 1993.

INSTITUTO DE APOIO ÀS PEQUENAS E MÉDIAS EMPRESAS E À INOVAÇÃOIAPMEI. Definição de PME. Disponível em: <http://www.iapmei.pt/iapmei-art03.php?id=1790> Acesso em: 23 nov. 2015.

INSTITUTO NACIONAL DE ESTATÍSTICA-INE. Empresas de Portugal 2012. Lisboa: INE, 2014.

Disponível:

https://www.ine.pt/xportal/xmain?xpid=INE\&xpgid=ine_publicacoes\&PUBLICACOESpub boui=210758098\&PUBLICACOESmodo=2> Acesso: 08 dez. 2015.

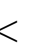


JULIEN, Pierre-André (org.). O Estado da arte da pequena e média empresa: fundamentos e desafios. Florianópolis: UFSC, 2013.

KAPLINSKY, Raphael. Firm size and Technical change in a dynamic context. The journal of Industrial Economics, vol XXXII, september 1983. IN: FREEMAN, Christopher. The economics of innovation. England: Edward Elgar Publiching Company, 1990, p. 313-333. KOTLER, Philip; DE BES, Fernando Trías. Inovar para ganhar: O modelo A-F. Coimbra: Conjuntura Actual, 2011.

MOWERY, David C.; ROSENBERG, Nathan. Trajetórias da inovação: a mudança tecnológica nos Estados Unidos da América no século XX. Campinas: UNICAMP, 2005.

NELSON, Richard. As fontes do crescimento econômico. Campinas: Unicamp, 2006.

OCDE- FINEP. MANUAL DE OSLO: proposta de diretrizes para a coleta e interpretação de dados sobre inovação tecnológica. OCDE, FINEP, 2004.

OCDE; EUROSTAT / FINEP. MANUAL DE OSLO: proposta de diretrizes para a coleta e interpretação de dados sobre inovação tecnológica. $3^{\mathrm{a}}$ ed. OCDE, EUROSTAT, FINEP, 2005.

POSSAS, Mário. Concorrência schumpeteriana. In: KUPFER, D.; HASENCLEVER, L. (org.). Economia Industrial: Fundamentos Teóricos e Práticas no Brasil. Rio de Janeiro: Campus, 2002.

PAVITT, Keith. Sectorial patterns of technical change: toward a taxonomy and a theory. 1984. IN: FREEMAN, Christopher. The economics of innovation. England: Edward Elgar Publiching Company, 1990, p. 249-279.

REDESIST. Rede de pesquisa em sistemas e arranjos produtivos e Inovativos locais. Disponível: < http://www.redesist.ie.ufrj.br/> Acesso em: 01 mar. 2016.

ROTHWELL, Roy. Industrial innovation: success, strategy, trends. In: DODGSON, Mark; ROTHWELL, Roy. The handbook of industrial innovation. England: Edward Elgar, 1994.

ROTHWELL, Roy; DODGSON, Mark. Innovation and size of firm. In: DODGSON, Mark; ROTHWELL, Roy. The handbook of industrial innovation. England: Edward Elgar, 1994.

SIMÕES, Marta; ANDRADE, João Sousa; DUARTE, Adelaide. In: ALEXANDRE, Fernando; BAÇÃO, Pedro; LAINS, Pedro; MARTINS, Manuel M. F.; PORTELA, Miguel; SIMÕES, Marta (orgs.). A economia portuguesa na União Europeia: 1986 - 2010. Coimbra: Conjuntura Actual, 2014.

SOETE, Luc. L. G. Firm size and inventive activity: the evidence reconsidered. European Economic Review, dez. 1979, pp. 319-340. IN: FREEMAN, Christopher. The economics of innovation. England: Edward Elgar Publiching Company, 1990, p. 291-312.

STIGLITZ, Joseph E.. Os exuberantes anos 90: uma nova interpretação da década mais próspera da história. São Paulo: Companhia das Letras, 2003. 